\title{
Pretreatment of high strength waste emulsions by combined vibratory shear enhanced process with Fenton oxidation
}

\author{
W. J. Zhang $\cdot$ M. Zhang $\cdot$ F. Xiao $\cdot$ L. P. Fang $\cdot$ \\ D. S. Wang
}

Received: 7 February 2012/ Accepted: 24 February 2013/Published online: 16 March 2013

(C) Islamic Azad University (IAU) 2013

\begin{abstract}
Pretreatment of waste emulsions with high organic content by a combined process of vibratory shear enhanced process and Fenton's oxidation prior to biological treatment was investigated. Vibrating membrane had shown good performance in chemical oxygen demand and oil removals and the mitigation of concentration polarization. However, the permeate after filtration processing still contained high content of organics. Thus, additional Fenton oxidation was applied to reduce the organic loading, and improve the biodegradability of the wastewater. The optimal molar ratio of ferrous iron to hydrogen peroxide was 0.05 obtained from the jar-test experiments. Removal of organics was enhanced by increasing hydrogen peroxide dosage, while efficiency of hydrogen peroxide reached maximum of $1.11(\mathrm{w} / \mathrm{w})$ at the hydrogen peroxide dosage of $6.8 \mathrm{~g} / \mathrm{L}$. Furthermore, the biological experiments indicated that the high concentration of organics could inhibit microbial activity, which decreased the chemical oxygen demand
\end{abstract}

Electronic supplementary material The online version of this article (doi:10.1007/s13762-013-0217-0) contains supplementary material, which is available to authorized users.

W. J. Zhang · F. Xiao ( ()$\cdot$ L. P. Fang · D. S. Wang

Research Center for Eco-Environmental Sciences,

Chinese Academy of Sciences,

Beijing 100085, China

e-mail: fengxiao@rcees.ac.cn

W. J. Zhang $\cdot$ M. Zhang

School of Resources and Environmental Science,

East China Normal University,

Shanghai 200062, China

L. P. Fang

Department of Basic Sciences and Environment,

Faculty of Life Sciences, University of Copenhagen,

Thorvaldsensvej 40, 1871 Frederiksberg C, Denmark degradation rates. The adaptive period of the microbe was greatly shortened using Fenton's reagent at the low dosages. The improvement of the biodegradability could be explained by partial mineralization and chemical transformation of parent organic compounds after Fenton oxidation.

Keywords Aerobic batch bioassay - Hydroxyl radical . Industrial wastewater - Integrated process - Ultrafiltration

\section{Introduction}

Waste emulsions with high organic content cause serious contamination and rancid odor due to the presence of complex chemicals, biocides, etc., hence, their treatment and final disposal must be handled carefully (Anderson et al. 2003). Traditional separation processes such as gravity, flotation and skimming are not so efficient to remove oils from water since oils have been chemically emulsified (Karakulski et al. 1995). Ultrafiltration (UF) is one of the most promising technologies for oil removal, thanks to the advantages of chemical additive-free and high oil rejection (Karakulski et al. 1995). However, the permeate flux of traditional membrane separation decreases rapidly with time due to membrane fouling and concentration polarization. Therefore, various physicochemical methods have been used to maintain a stable permeate flux, such as adding reactive salt (Belkacem et al. 1995), coagulation pretreatment (Zhong et al. 2003) and dynamic shear enhanced processes, i.e., rotating membranes and vibratory shear enhancing process (VSEP) (Jaffrin 2008). VSEP can efficiently prevent concentration polarization and membrane fouling in the process of emulsions filtration by producing high frequency of shear. Consequently, a high flux can be achieved at low feeding pressure, resulting in 
low energy consumption but high treatment capacity (Al Akoum et al. 2002; Moulai-Mostefa et al. 2007, 2010; Jaffrin 2008).

Besides, it is commonly observed that permeate after UF contains high content of organics mainly including surfactants and biocides, which requires an additional biological treatment for the permeate. Whereas, high concentration of surfactants and biocides could cause a series of physiological responses and dysfunction of microbes and in their cells. For example, once the concentration of surfactant in wastewater exceeds $1,000 \mathrm{mg} / \mathrm{L}$, microbial activity will be inhibited seriously and foaming can occur in aeration tank (Aloui et al. 2009), which can significantly influence the removal efficiency of biological treatment. Thus, a chemical oxidation step is normally required to reduce organic loading and toxicity of wastewater prior to biological processing (Kitis et al. 1999; Pignatello et al. 2006). Fenton oxidation has been proven to be an effective way to reduce organic loading (Lin et al. 1999) and improve biodegradability of industrial wastewater containing biorefractory compounds, such as surfactants (Kitis et al. 1999), dyes (Gharbani et al. 2008) and pharmaceuticals (Deegan et al. 2011). This technology depends on in situ producing a non-selective strong hydroxyl radical which can oxidize various organic matters at ambient condition (Gogate and Pandit 2004).

This study proposed an integrated process of VSEP, Fenton oxidation and biological technology to treat the waste emulsions with high organic content. The objective of this study was to investigate: (1) the effect and performance of VSEP in oil removal and mitigation of concentration polarization; (2) the optimal operating conditions were determined by considering both $\mathrm{H}_{2} \mathrm{O}_{2}$ efficiency and biodegradability improvement in Fenton process; (3) influence of initial concentration of organic matters and Fenton oxidation on biodegradability of permeate using aerobic batch bioassays; (4) the feasibility and effects of using the integrated process for treating waste emulsion in full-scale application. The laboratory-scale experiment was carried out in School of Resources and Environmental Science, East China Normal University (Shanghai, China), from April to October 2010. The full-scale treatment facility was operated stably for 8 months (June 2011-April 2012) at the Shanghai Chemical Industry Park.

\section{Materials and methods}

Waste emulsions

The three oil-in-water $(\mathrm{O} / \mathrm{W})$ emulsions used in this study were obtained from an appliance manufacturer and an electronic accessory producer and metal working corporation. The characteristics of the emulsions are presented in Table 3.

Emulsions treatment

\section{Filtration of emulsions by VSEP}

The filtration module is depicted in Fig. 1. The shaft supporting the membrane module serves as the function of a torsion spring, which transmits oscillations created by an eccentric driving motor. The displacement amplitude and oscillation frequency of the equipment were fixed at $2 \mathrm{~cm}$ and $50 \mathrm{~Hz}$, respectively. The permeate from the membrane filtration passes through the permeate tubing which locates upon the spring under atmospheric pressure. The concentrated stream permeates through the "out" line. The return flow passes through the flow limiter and the control valve allowing the fine adjustment of outlet pressure. A "Y-trap" and bypass valve for adjusting the inlet pressure is equipped at the inlet and outlet of pump, respectively. Meanwhile, the transmembrane pressure (TMP) is estimated as the mean value of the inlet and outlet pressure (MoulaiMostefa et al. 2010), and the inlet and outlet pressures were kept constant at 344.8 and $125 \mathrm{kPa}$. Membrane flux is measured in accordance with the volume of fluid within a certain period. Each run is stopped after reaching $80 \%$ permeate recovery. The operating conditions of VSEP are given in Table 2. Membrane is made of hydrophilic polyethersulfone with $150 \mathrm{kDa}$ nominal cut-off, and the effective area is $1.54 \mathrm{~m}^{2}$. The detailed features of the membrane can be found in Table 1. Molecular weights of Dextran T2000 and T500 are 2,000 and $500 \mathrm{kDa}$.

\section{Fenton's oxidation of VSEP permeate}

The $\mathrm{pH}$ of permeate was adjusted to 3.0 before the Fenton oxidation experiments. $500 \mathrm{~mL}$ of permeate was added in an $800-\mathrm{mL}$ beaker. The beaker was placed in thermostatic bath $\left(25 \pm 1^{\circ} \mathrm{C}\right)$. Then, appropriate amounts of ferrous sulfate heptahydrate salt $\left(\mathrm{FeSO}_{4} \cdot 7 \mathrm{H}_{2} \mathrm{O}\right)$ were added in the beaker to achieve desired concentration of ferrous ions. Finally, an aliquot of $\mathrm{H}_{2} \mathrm{O}_{2}(30 \%(\mathrm{w} / \mathrm{v}))$ was spiked in the solution under vigorous stirring using a magnetic stirrer. The reaction was stopped by raising the $\mathrm{pH}$ of the solution to 12 , after 3 -h stirring, and then the mixture was boiled for $10 \mathrm{~min}$ to remove $\mathrm{H}_{2} \mathrm{O}_{2}$ prior to chemical oxygen demand (COD) analysis. Note that boiling process does not affect the COD determination. The suspension was poured into a graduated cylinder to allow the precipitate settles down until lower than $20 \%$ of the total volume. The supernatant was collected from the cylinder. The COD values of the supernatant and precipitate were determined. 
Fig. 1 A schematic presentation of the vibrating membrane equipment

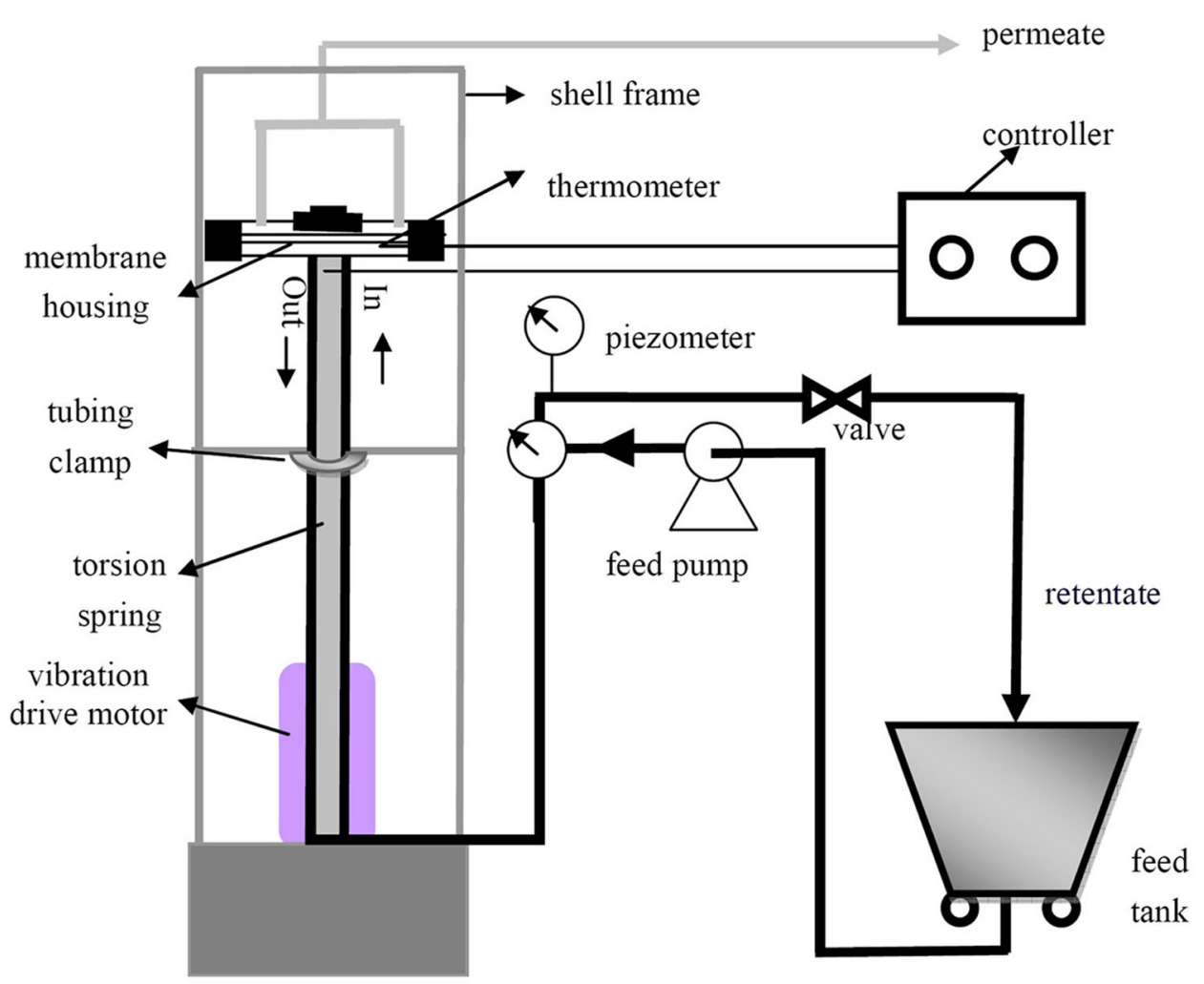

Table 1 Technical data of UF-19 membrane $\left(70 \mathrm{kPa}, 20{ }^{\circ} \mathrm{C}\right.$, stirred cell: $700 \mathrm{rpm}$ )

\begin{tabular}{llll}
\hline Test solute rejection $(\%)$ & $\begin{array}{l}\text { Pure water flux } \\
\left(\mathrm{L} \mathrm{m}^{-2} \mathrm{~h}^{-1}\right)\end{array}$ \\
\hline $\begin{array}{l}\text { Dextran T2000 } \\
(1 \%)\end{array}$ & $\begin{array}{c}\text { Dextran T500 } \\
(1 \%)\end{array}$ & $70 \mathrm{kPa}$ & $300 \mathrm{kPa}$ \\
$87-92$ & $50-60$ & $300-600$ & $1,200-2,100$ \\
\hline
\end{tabular}

\section{Biodegradability assessment}

Aerobic batch bioassay was adopted to assess the biodegradability of permeate. This approach has been described in details elsewhere (Adams et al. 1997; Kitis et al. 1999). Briefly, the bioassays were conducted by adding $300 \mathrm{~mL}$ of sample into a 500-mL of Erlenmeyer flask. The water sample was incubated with a microbial seed from aeration tank in Quyang wastewater treatment plant, Shanghai), after spiking an aliquot of nutrient solution. In order to examine the influence of concentration of organics on the microbial activity, permeate with COD concentrations of $1,000,5,000$ and $10,000 \mathrm{mg} / \mathrm{L}$ were examined. In addition, batch bioassays were also conducted on the permeate with/ without Fenton's oxidation at an initial COD concentration of $1,000 \mathrm{mg} / \mathrm{L}$. The supernatant was filtrated through $0.45 \mu \mathrm{m}$ membrane filter before COD analysis. Sample was considered biodegradable when the measured COD in solution decreased over $70 \%$ after biological treatment.
Water quality analysis

Hydrogen peroxide was measured using iodometric method. Oil concentrations in the feed and permeate solutions were analyzed using gravimetric method after extracting with petroleum ether according to the National Standard of China CJ/T51-2004, while COD was measured using the potassium dichromate method based on the National Standard of China GB 119 14-89. Content of suspended solid (SS) and $\mathrm{pH}$ was also determined by gravimetric and electrometric methods, respectively.

\section{Results and discussion}

Waste emulsions treatment by VSEP

\section{Effects of emulsions treatment by vibrating membrane}

The effects of VSEP on removal of COD, oil, and SS were presented in Table 2. Due to the different sources and composition of water sample, the removal efficiency of COD and oil was different. But apparently, SS was completely rejected. The recovery of permeate in each water sample was more than $80 \%$. The range of hydrophiliclipophilic balance (HBL) values of emulsifiers used in O/W emulsion is from 8 to 18 . This indicated that the adhesive force between water and surfactant was stronger than that 
Table 2 Experimental results of treatment of three waste emulsions by VSEP

\begin{tabular}{|c|c|c|c|c|c|c|c|}
\hline \multirow[t]{2}{*}{ Sample } & \multirow[t]{2}{*}{$\mathrm{pH}$} & \multicolumn{2}{|c|}{ COD (mg/L) } & \multicolumn{2}{|c|}{ Oil (mg/L) } & \multicolumn{2}{|c|}{$\mathrm{SS}(\mathrm{mg} / \mathrm{L})$} \\
\hline & & Feed & Permeate & Feed & Permeate & Feed & Permeate \\
\hline A & 7.3 & 31,100 & 4,840 & 2,280 & 335 & 2,075 & 0 \\
\hline B & 8.0 & 117,100 & 24,820 & 876 & 92 & 5,490 & 0 \\
\hline $\mathrm{C}$ & 9.2 & 235,300 & 32,600 & 12,296 & 54 & 0 & 0 \\
\hline
\end{tabular}

between oil and surfactants. Thus, the surfactants and additives with low molecular weight could pass through membrane instead of being rejected along with oil. As a result, the UF permeate still had a high COD level.

\section{Membrane flux}

The classical resistance-in-series model can be written in our case as (Belkacem et al. 1995):

$J=\frac{\Delta P}{\mu\left(R_{\mathrm{M}}+R_{\mathrm{ads}}+R_{\mathrm{P}}\right)}$

where $J$ denotes membrane flux, $\Delta P$ is transmembrane pressure, $\mu$ is permeate viscosity. $R_{\mathrm{M}}, R_{\text {ads }}$ and $R_{\mathrm{P}}$ represent intrinsic membrane resistance, adsorption resistance of solute molecules and concentration polarization resistance, respectively. As shown in Eq. 1, the decrease of permeate flux was mainly ascribed to the formation and accumulation of oil and O/W gel layers on the membrane surface. Furthermore, adsorption of surfactants resulted in reduction of surface porosity of membrane (Lin and Lan 1998; Marchese et al. 2000; Benito et al. 2001; Janknecht et al. 2004).

Figure 2 demonstrated the changes of membrane flux and temperature of the samples $\mathrm{A}$ and $\mathrm{C}$ during filtration. Because of the frictional heating contributed by high-speed shear force of vibrating membrane, the increase of the temperature of each sample was almost linear to time. The flux of the sample A stably maintained in the range of $47-52 \mathrm{~L} \mathrm{~m}^{-2} \mathrm{~h}^{-1}$, while the flux of the sample $\mathrm{C}$ increased significantly from 23 to $37 \mathrm{~L} \mathrm{~m}^{-2} \mathrm{~h}^{-1}$ during filtration processing. These results demonstrated that the VSEP could effectively reduce the concentration polarization of the membrane via high shear rates. However, Moulai-Mostefa et al. (2007), (2010) reported that the membrane flux decreased with time due to the increase of oil concentration at constant temperature and pressure. These inconsistent findings regarding flux, from our results, could be explained by the increase of the sample temperature. It is well known that the higher temperature can decrease viscosity of water, and consequently, increase the permeability through membrane. The increased temperature could counteract the flux decline caused by the increase of oil concentration. Therefore, the membrane flux can be effectively enhanced by increasing the temperature of wastewater.
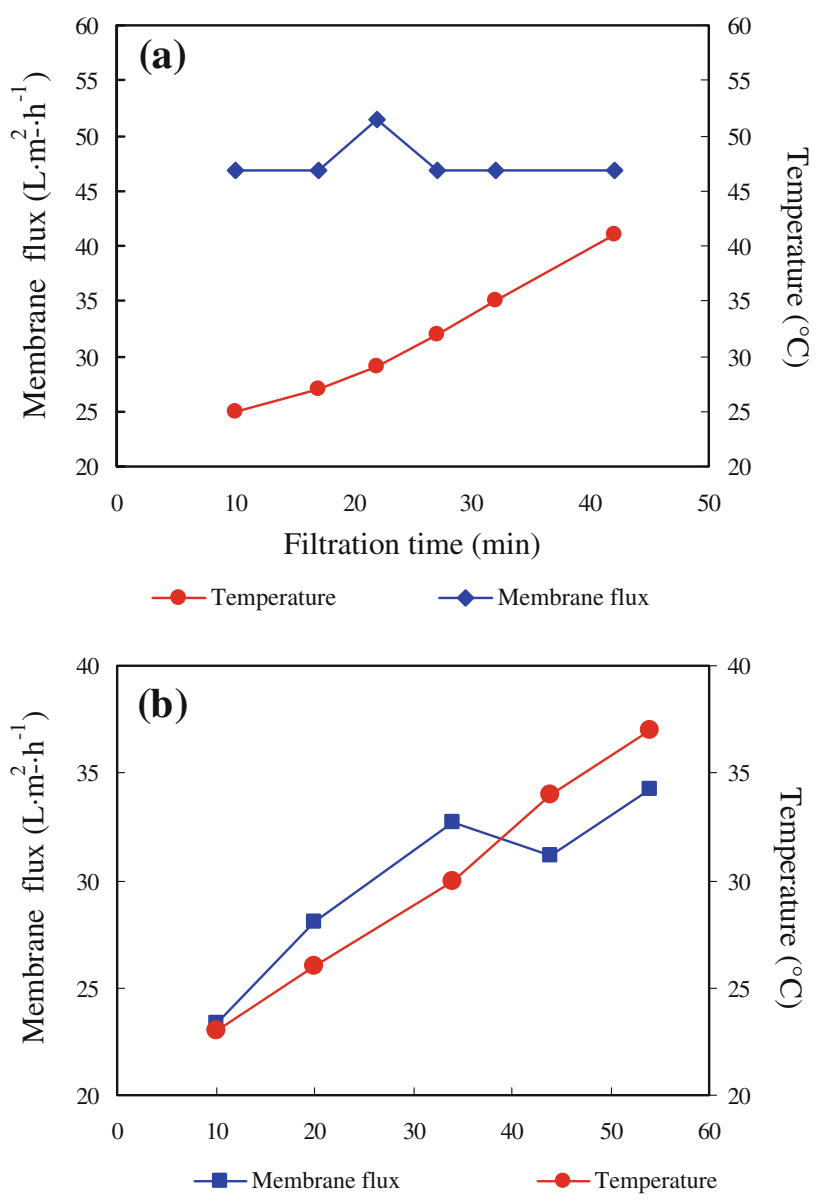

Filtration time (min)

Fig. 2 Changes of membrane flux and temperature of water samples during filtration by VSEP: a sample A; b sample C

Fenton oxidation

$\left[\mathrm{Fe}^{2+}\right] /\left[\mathrm{H}_{2} \mathrm{O}_{2}\right]$

Permeate was mixed together according to the real wastewater prior to experiment. The COD content in the mixture was $21,975 \mathrm{mg} / \mathrm{L}$. Figure $3 \mathrm{a}$, b illustrated the influence of the ferrous dosage on COD removal at the initial $\left[\mathrm{H}_{2} \mathrm{O}_{2}\right] /[\mathrm{COD}]$ weight ratios of 1.55 and 0.77 , respectively. It was found that the optimum range of ferrous dosage to achieve the maximum organic mineralization was from 1.4 to $2.8 \mathrm{~g} / \mathrm{L}$ (corresponding molar ratio of ferrous and $\mathrm{H}_{2} \mathrm{O}_{2}$ was $0.05 \sim 0.1$ ). 
The COD removal rate could be achieved to 61 and $69 \%$ when $\mathrm{H}_{2} \mathrm{O}_{2} / \mathrm{COD}$ (w/w) ratio was 0.77 and 1.55 , respectively. When the ferrous dosage was less than $1.4 \mathrm{~g} / \mathrm{L}$, the decomposition of organics was inhibited. Besides, the residual hydrogen peroxide in the solution could be also observed after 3 -h reaction (data not shown). The ferrous ions reacted very rapidly with hydrogen peroxide to produce hydroxyl radicals (reaction 2) which could decompose organics quickly, and then ferric ions were reduced to ferrous ions by hydrogen peroxide (reactions 4 and 5). However, the rate of oxidation in the second stage (ferric system) was much slower than in the first one due to the low generation rate of ferrous from ferric ions (Neyens and Baeyens 2003; Pignatello et al. 2006). The removal of COD slightly decreased as the initial dosage of ferrous was over $2.8 \mathrm{~g} / \mathrm{L}$. This was attributed to the competition of reactions 3 and 6 , even although this type of competition was negligible at high $\mathrm{COD} / \mathrm{H}_{2} \mathrm{O}_{2}$ ratios (Neyens and Baeyens 2003).

$$
\begin{aligned}
& \mathrm{Fe}^{2+}+\mathrm{H}_{2} \mathrm{O}_{2} \rightarrow \mathrm{Fe}^{3+}+\cdot \mathrm{OH}+\mathrm{OH}^{-} \\
& \cdot \mathrm{OH}+\mathrm{Fe}^{2+} \rightarrow \mathrm{Fe}^{3+}+\mathrm{OH}^{-} \\
& \mathrm{Fe}^{3+}+\mathrm{H}_{2} \mathrm{O}_{2} \leftrightarrow \mathrm{Fe}-\mathrm{OOH}^{2+}+\mathrm{H}^{+} \\
& \mathrm{Fe}-\mathrm{OOH}^{2+} \rightarrow \mathrm{HO}_{2} \cdot+\mathrm{Fe}^{2+} \\
& \mathrm{RH}+\cdot \mathrm{OH} \rightarrow \mathrm{H}_{2} \mathrm{O}+\mathrm{R} \cdot \rightarrow \text { further oxidation }
\end{aligned}
$$

The ferrous ions generated in the above redox reactions could react with hydroxide ions to form ferric hydroxo complexes which acted as coagulant to capture and precipitate with suspended particles (Bautista et al. 2008). Such coagulation/precipitation behavior played an important role in COD removal of leachate, since it had a high concentration of SS that can be easily removed by coagulation (Kang and Hwang 2000). The removal of COD by oxidation and coagulation was also demonstrated in Fig. 3. The removal rate showed similar trends at the $\mathrm{H}_{2} \mathrm{O}_{2} /$ COD weight ratios of 1.51 and 0.77 (Fig. 3a, b). Apparently, the COD removal ratio through ferric hydroxide coagulation was less than $10 \%$ at both $\mathrm{H}_{2} \mathrm{O}_{2}$ /COD weight ratios. The result indicated that it cannot improve the contribution of coagulation in overall organic removal with increasing ferrous dosage, say more than $14 \mathrm{~g} / \mathrm{L}$. This could be explained that surfactants used in $\mathrm{O} / \mathrm{W}$ emulsions were hydrophilic dissolved organics $\left(\log K_{\text {OW }}\right.$ values less than 3 ; Shon et al. 2006). This was in agreement with the result from Bautista et al. (2008), who reported that coagulationflocculation had a poor effect on the removal of soluble organic compounds such as reactive dyes.

\section{The influence of hydrogen peroxide dosage on its efficiency}

Figure 4 showed that the efficiency of $\mathrm{H}_{2} \mathrm{O}_{2}$ reached a maximum value of 1.11 ( $\mathrm{g} \mathrm{COD}$ removed $/ \mathrm{g} \mathrm{H}_{2} \mathrm{O}_{2}$ ) when
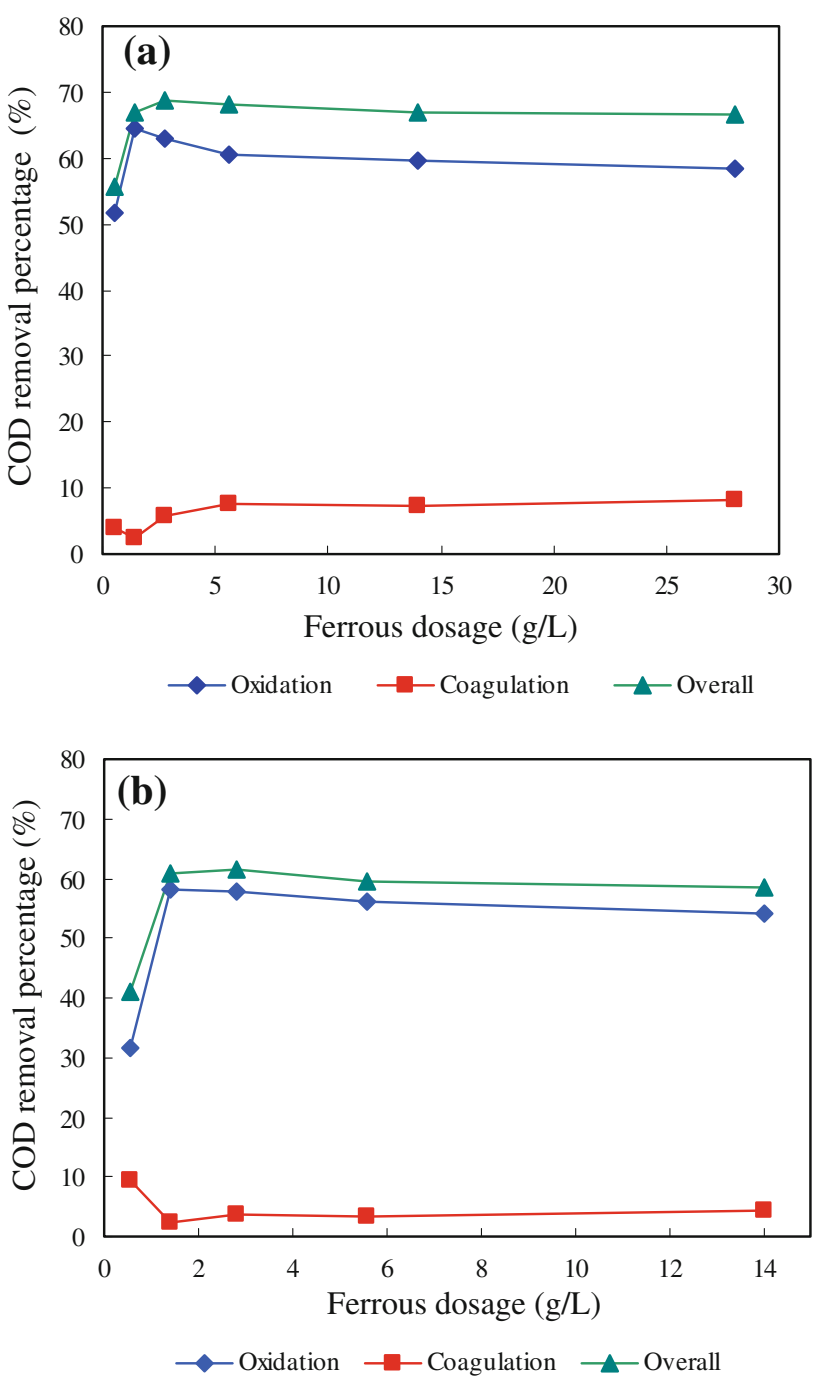

Fig. 3 Influence of ferrous dosage on COD removal ratio by oxidation and coagulation: a $\mathrm{H}_{2} \mathrm{O}_{2} / \mathrm{COD}(\mathrm{w} / \mathrm{w})=1.55 ;$ b $\mathrm{H}_{2} \mathrm{O}_{2}$ / $\operatorname{COD}(\mathrm{w} / \mathrm{w})=0.77$

the dosages of $\mathrm{H}_{2} \mathrm{O}_{2}$ and ferrous ion were 6.8 and $2.8 \mathrm{~g} / \mathrm{L}$, respectively. The $\mathrm{H}_{2} \mathrm{O}_{2}$ efficiency improved when $\mathrm{H}_{2} \mathrm{O}_{2}$ dosage was below this value, whereas the removal efficiency drastically decreased at a higher $\mathrm{H}_{2} \mathrm{O}_{2}$ dosage. In the case of serving low ferrous dosage in the solution, it is rational to assume that ferric ions formed from Fenton reaction might complex with certain organic ligands; consequently, the "passivated" ferric ions could no longer participate in the regeneration reaction of ferrous ions through ferric system. This might weaken the oxidation processing, as well as $\mathrm{H}_{2} \mathrm{O}_{2}$ efficiency. The causes for the latter were more complex; there might be some organics or partially oxidized intermediates which were resistant to chemical oxidation and could not be effectively removed by Fenton's reagent. On the other hand, ferrous ions were added in the form of sulfate salt. Due to the occurrence of complexation reactions of $\mathrm{Fe}(\mathrm{III})$ by $\mathrm{SO}_{4}^{2-}$ (reactions 7 and 


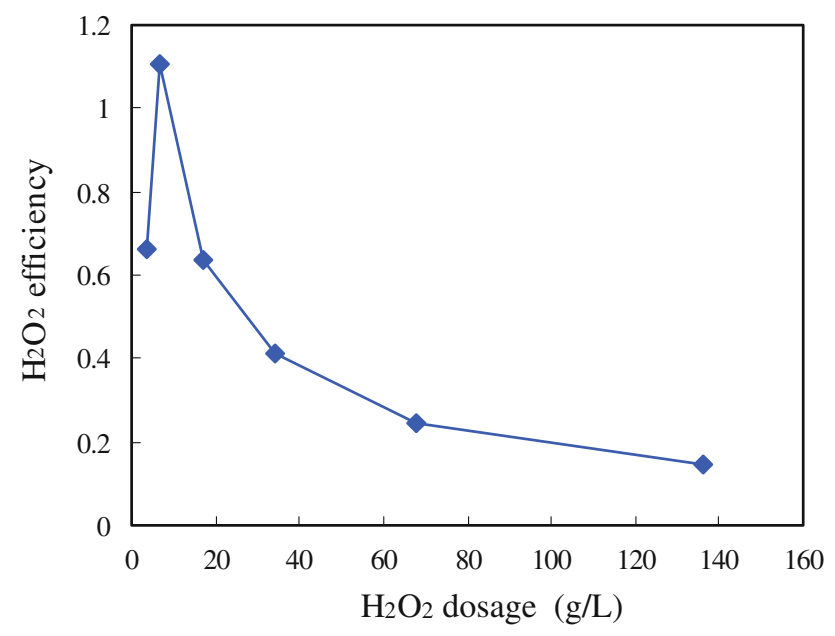

Fig. 4 Effect of hydrogen peroxide dosage on its efficiency $\left(\mathrm{Fe}^{2+} /\right.$ $\mathrm{H}_{2} \mathrm{O}_{2}$ molar ratio, $\mathrm{pH}$, and reaction time were fixed as approximately $0.05,3$, and $3 \mathrm{~h}$, respectively.)

8), the increase of the $\mathrm{SO}_{4}^{2-}$ concentration could lead to a decrease of the concentration of peroxo complexes, and consequently, a decrease of decomposition rate of $\mathrm{H}_{2} \mathrm{O}_{2}$ (De Laat et al. 2004). In addition, the sulfate anion in the solution could act as a hydroxyl radical scavenger and react with $\cdot \mathrm{OH}$ according to reactions 9 and 10 (De Laat et al. 2004; Siedlecka and Stepnowski 2007), resulting in a decrease of degradation.

$$
\begin{aligned}
& \mathrm{Fe}^{3+}+\mathrm{SO}_{4}^{2-} \leftrightarrow \mathrm{FeSO}_{4}^{+} \\
& \mathrm{Fe}^{3+}+2 \mathrm{SO}_{4}^{2} \leftrightarrow \mathrm{Fe}\left(\mathrm{SO}_{4}\right)_{2}^{-} \\
& \mathrm{H}_{2} \mathrm{SO}_{4}+\cdot \mathrm{OH} \rightarrow \mathrm{SO}_{4}^{-} \cdot+\mathrm{H}^{+}+\mathrm{H}_{2} \mathrm{O} \\
& \mathrm{HSO}_{4}^{-}+\cdot \mathrm{OH} \rightarrow \mathrm{SO}_{4}^{-} \cdot+\mathrm{H}_{2} \mathrm{O}
\end{aligned}
$$

Influence of initial organic content and Fenton oxidation on biodegradability of wastewater

The performance and efficacy of biological treatment was affected significantly by composition and concentration of the toxic organic matters in wastewaters, especially industrial wastewaters containing high strength organics. Thus, biodegradability of raw permeate was analyzed at three dilutions $(1: 1,1: 4$, and 1:10) to understand the behavior of sludge in contact with wastewater with initial different concentrations. Note that each flask was spiked with an appropriate amount of activated sludge to yield the same initial food-to-microorganisms (F/M) ratio. As shown in Fig. 5, the ultimate COD degradation rates are 75, 59, and $41 \%$ when unoxidized filtrate was also bioassayed at $1,000,5,000$, and 10,000 $\mathrm{mg} / \mathrm{L}$ as COD, respectively. The high content might be possibly inhibitory to sludge metabolism and resulted in low biodegradation rate. Therefore, chemical pre-oxidation was a required step to eliminate this concentration effect.

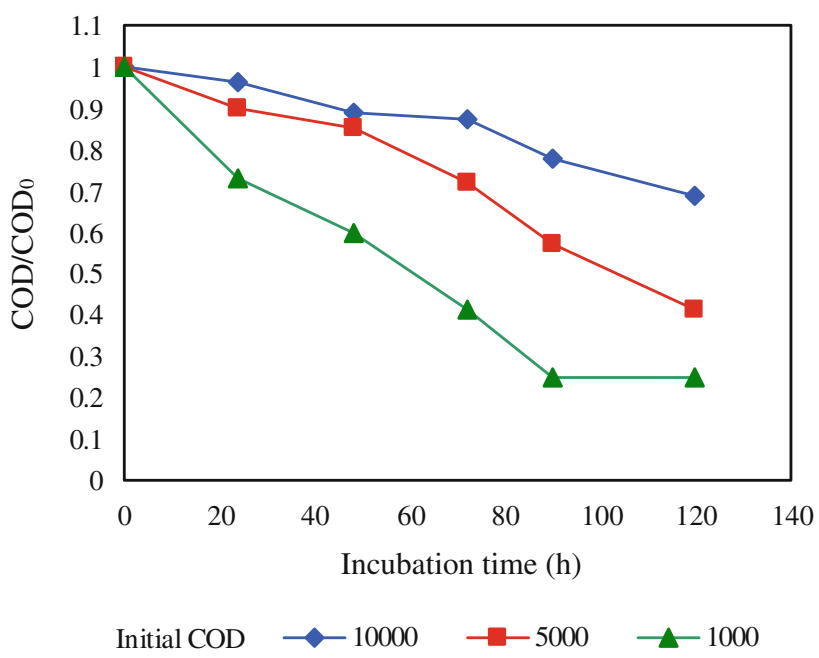

Fig. 5 Influence of initial organic concentration on biodegradability

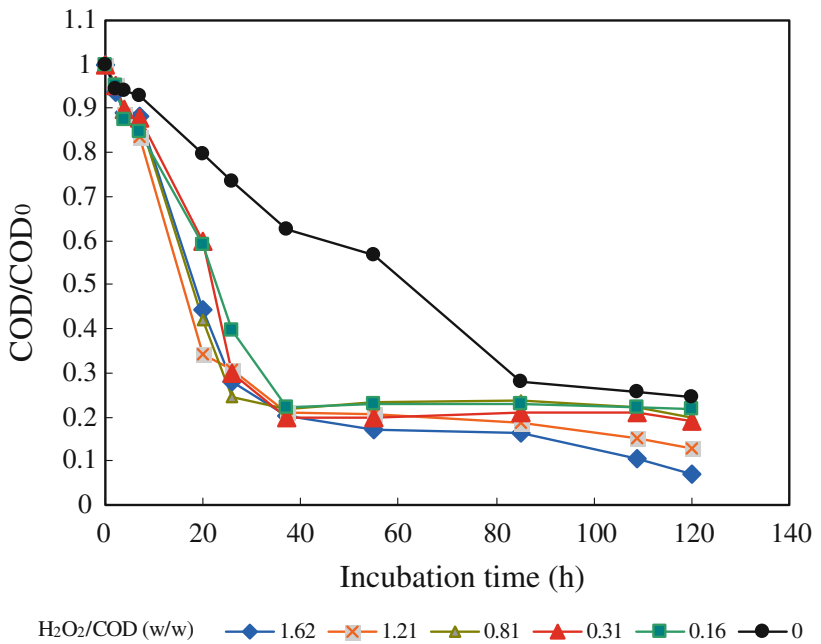

Fig. 6 Influence of $\mathrm{H}_{2} \mathrm{O}_{2} / \mathrm{COD}(\mathrm{w} / \mathrm{w})$ on biodegradability $\left(\mathrm{Fe}^{2+}\right.$ / $\mathrm{H}_{2} \mathrm{O}_{2}$ molar ratio, $\mathrm{pH}$, and reaction time were fixed as approximately $0.05,3$, and $3 \mathrm{~h}$, respectively.)

As stated previously, application of Fenton's reagent was an efficient way to reduce organic content of this wastewater through complete mineralization via the generation of hydroxyl radicals, but the effect of Fenton oxidation on degradability of this wastewater was unknown. Therefore, aerobic batch bioassays were also conducted to evaluate the biodegradability of oxidized and unoxidized samples at initial concentrations of $1,000 \mathrm{mg} / \mathrm{L}$ as COD. For all samples, $70 \%$ biodegradability was attained after $90 \mathrm{~h}$ of biotreatment (Fig. 6). Oxidized samples were biodegradable after only $24 \mathrm{~h}$ even at a low dosage of Fenton's reagent, but untreated sample needed much longer adaptation periods $(90 \mathrm{~h})$. These results indicated that using Fenton's reagent could accelerate bio-oxidation rate by converting the biorefractory compounds (surfactants and additives) into small concentration of organic intermediates 
Fig. 7 Full-scale process for treating waste emulsions and other industrial wastewaters

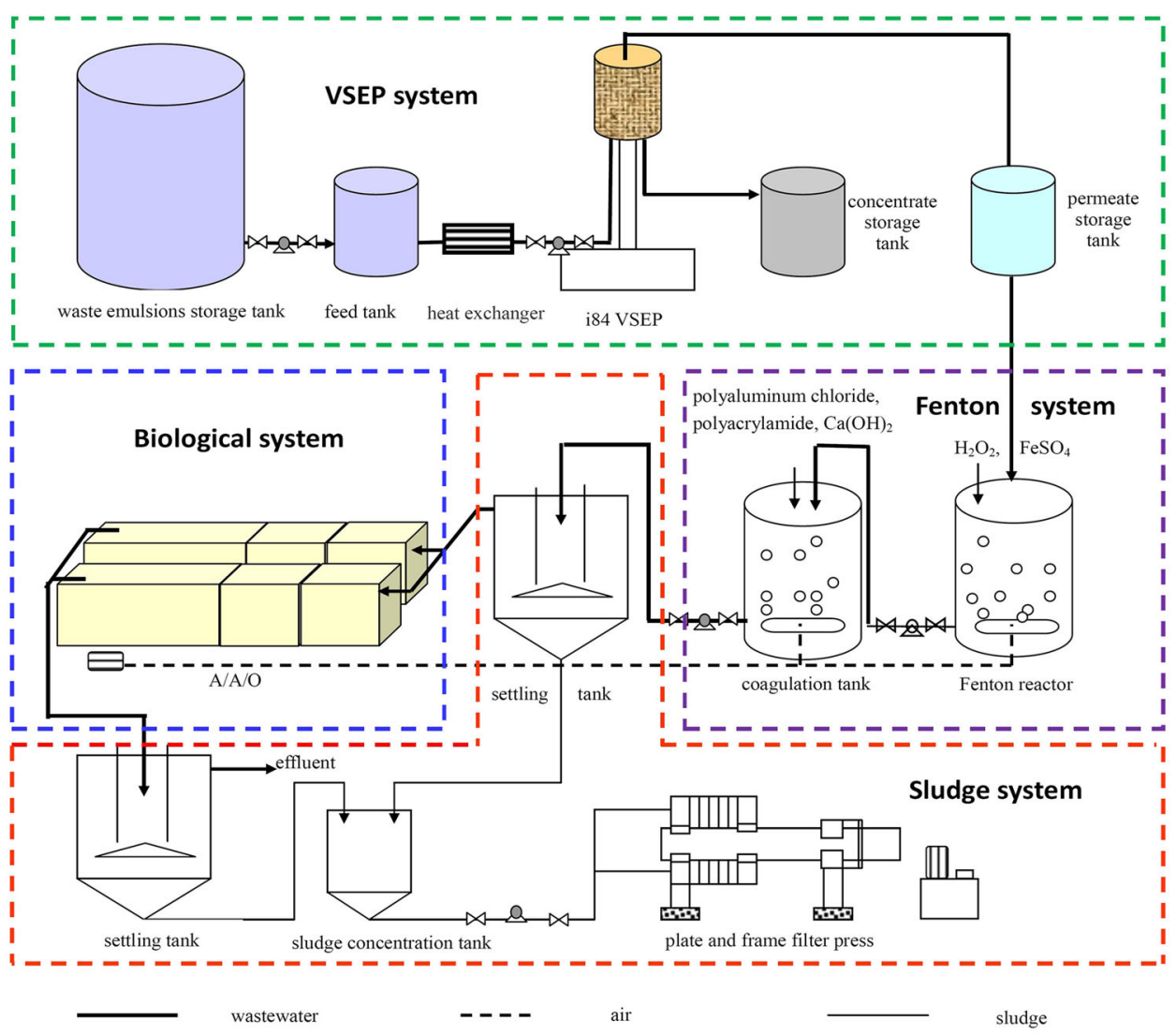

such as carboxylic acids, formic acid or formaldehyde that were more biodegradable. When the dosages of hydrogen peroxide and ferrous iron were 6.8 and $2.8 \mathrm{~g} / \mathrm{L}$, ultimate biodegradation rate of wastewater increased up to $81 \%$. No significant improvement of bio-oxidation rate was observed with the further increase in $\mathrm{H}_{2} \mathrm{O}_{2}$ dosages. Considering the above results about $\mathrm{H}_{2} \mathrm{O}_{2}$ efficiency, this dosage could be used to yield sufficient wastewater biodegradability and minimize the hydrogen peroxide consumption.
Full-scale application

This integrated process has been successfully applied to treat various emulsions and other industrial wastewaters, such as passivation liquid, paint wastewater, metal surface treatment liquid and organic solvent wastewater by recombination of several treatment units (coagulation-flocculation, Fenton oxidation, VSEP, anaerobic-anoxic-aerobic treatment) in Shanghai industrial park. The design capacity of wastewater

Table 3 Operating conditions and COD removal efficiency of each treatment unit

\begin{tabular}{|c|c|c|c|c|c|c|}
\hline \multirow{2}{*}{$\begin{array}{l}\text { Stage } \\
\text { VSEP }\end{array}$} & \multicolumn{5}{|c|}{ Operating conditions } & \multirow{2}{*}{$\begin{array}{l}\text { Effects } \\
\text { COD }(\mathrm{mg} / \mathrm{L})^{\mathrm{a}}\end{array}$} \\
\hline & DA $(\mathrm{cm})$ & $P_{\text {in }}(\mathrm{kPa})$ & \multicolumn{2}{|c|}{$P_{\text {out }}(\mathrm{kPa})$} & $T\left({ }^{\circ} \mathrm{C}\right)$ & \\
\hline & 2 & 414 & \multicolumn{2}{|c|}{$207-310$} & $60-80$ & $11,000 \pm 2,000$ \\
\hline \multirow[t]{2}{*}{ Fenton oxidation } & Initial $\mathrm{pH}$ & $\mathrm{H}_{2} \mathrm{O}_{2}$ dose $(\mathrm{v} / \mathrm{v})$ & \multicolumn{2}{|c|}{ Ferrous dose $(\mathrm{g} / \mathrm{L})$} & Reaction time (h) & COD (mg/L) \\
\hline & $3-3.5$ & $1 \%$ & 1.4 & & 3 & $6,000 \pm 2,000$ \\
\hline Biological system ${ }^{b}$ & $\mathrm{DO}(\mathrm{mg} / \mathrm{L})$ & HRT (day) & SRT (day) & Volur & $\operatorname{ng}\left(\mathrm{kg} \mathrm{COD} / \mathrm{m}^{3}\right.$ day $)$ & $\mathrm{COD}(\mathrm{mg} / \mathrm{L})$ \\
\hline Anaerobic & $0-0.2$ & 0.5 & $>300$ & $12 \pm$ & & $2,000 \pm 500$ \\
\hline Anoxic & $0.4-0.6$ & 0.5 & $>300$ & & & \\
\hline Aerobic & $2.5-3$ & 2 & $25-30$ & $1 \pm 0$ & & $400 \pm 100$ \\
\hline
\end{tabular}

$H R T$ hydraulic retention time, $S R T$ sludge retention time, $D A$ displacement amplitude, $D O$ dissolved oxygen, $T$ temperature

${ }^{\text {a }}$ Inlet COD content of VSEP was $130,000 \pm 30,000 \mathrm{mg} / \mathrm{L}$

${ }^{\mathrm{b}}$ Influent $\mathrm{pH}, \mathrm{TN}$ and TP were 7-8, $295 \pm 50 \mathrm{mg} / \mathrm{L}$ and $1.3 \pm 0.5 \mathrm{mg} / \mathrm{L}$ 
plant is $100 \mathrm{~m}^{3} /$ day, and entire flow diagram is depicted in Fig. 7. The anaerobic/anoxic/aerobic process $\left(\mathrm{A}^{2} / \mathrm{O}\right)$ was used for biological treatment. Each biochemical pond was filled with composite carriers to enhance the ability against shock loading. Operating parameters and the contribution of each stage to COD removal were given in Table 3 . The final effluent quality could reach the discharge standard for municipal sewerage system in Shanghai (DB31/445-2009).

\section{Conclusion}

In this study, a combination of VSEP and Fenton's oxidation was used to reduce organic loading and improve biodegradability for subsequent biological treatment of waste emulsions. More than $85 \%$ of oil could be removed for all three emulsions by VSEP, while COD removal efficiency varied widely. The flux was found to be very stable with time due to a high shear rate of VSEP and the increase in water temperature caused by frictional heating. However, high concentration of organic contaminants still remained in UF permeate, hence a further treatment was required to meet the wastewater discharge standards. Since the microbial activity was inhibited by the high concentrations of organics, resulting in a slow biodegradation rate, and the biodegradability was significantly enhanced by Fenton oxidation. The optimum molar ratio of ferrous and $\mathrm{H}_{2} \mathrm{O}_{2}$ was approximately 0.05. COD degradation rate did not linearly relate with the dosage of $\mathrm{H}_{2} \mathrm{O}_{2}$, and efficiency of $\mathrm{H}_{2} \mathrm{O}_{2}$ ascended firstly and decreased later with an increase in $\mathrm{H}_{2} \mathrm{O}_{2}$ dosage. The contribution of coagulation on the removal of organic matters in permeate was rather limited in Fenton process. The improvement of biodegradability was attributable to both formation of more biodegradable oxidized byproducts and reduction of organic loading in wastewater.

Acknowledgments This research was supported by grants from the National Natural Science Foundation of China (No. 5113808, 51008293). The authors also greatly appreciate financial support from the Shanghai Jihui Enviroment protection technology development co. Ltd.

\section{References}

Adams CD, Cozzens RA, Kim BJ (1997) Effects of ozonation on the biodegradability of substituted phenols. Water Res 31(10):2655-2663

Al Akoum O, Jaffrin MY, Ding LH, Paullier P, Vanhoutte C (2002) An hydrodynamic investigation of microfiltration and ultrafiltration in a vibrating membrane module. J Membrane Sci 197(1-2):37-52

Aloui F, Kchaou S, Sayadi S (2009) Physicochemical treatments of anionic surfactants wastewater: effect on aerobic biodegradability. J Hazard Mater 164(1):353-359

Anderson JE, Kim BR, Mueller SA, Lofton TV (2003) Composition and analysis of mineral oils and other organic compounds in metalworking and hydraulic fluids. Crit Rev Environ Sci Tech 33(1):73-109
Belkacem M, Matamoros H, Cabassud C, Aurelle Y, Cotteret J (1995) New results in metal-working waste-water treatment using membrane technology. J Membrane Sci 106(3):195-205

Benito JM, Ebel S, Gutierrez B, Pazos C, Coca J (2001) Ultrafiltration of a waste emulsified cutting oil using organic membranes. Water Air Soil Pollut 128(1-2):181-195

Bautista P, Mohedano AF, Casas JA, Zazo JA, Rodriguez JJ (2008) An overview of the application of Fenton oxidation to industrial wastewaters treatment. J Chem Tech Biotech 83(10):1323-1338

De Laat J, Le GT, Legube B (2004) A comparative study of the effects of chloride, sulfate and nitrate ions on the rates of decomposition of $\mathrm{H}_{2} \mathrm{O}_{2}$ and organic compounds by $\mathrm{Fe}(\mathrm{II}) / \mathrm{H}_{2} \mathrm{O}_{2}$ and $\mathrm{Fe}(\mathrm{III}) / \mathrm{H}_{2} \mathrm{O}_{2}$. Chemosphere 55(5):715-723

Deegan AM, Shaik B, Nolan K, Urell K, Oelgemöller M, Tobin J, Morrissey A (2011) Treatment options for wastewater effluents from pharmaceutical companies. Int J Environ Sci Technol 8(3):649-666

Gharbani P, Tabatabaii SM, Mehrizad A (2008) Removal of Congo red from textile wastewater by ozonation. Int $\mathrm{J}$ Environ Sci Technol 5(4):495-500

Gogate PR, Pandit AB (2004) A review of imperative technologies for wastewater treatment I: oxidation technologies at ambient conditions. Adv Environ Res 8(3-4):501-551

Jaffrin MY (2008) Dynamic shear-enhanced membrane filtration: a review of rotating disks, rotating membranes and vibrating systems. J Membrane Sci 324(1-2):7-25

Janknecht P, Lopes AD, Mendes AM (2004) Removal of industrial cutting oil from oil emulsions by polymeric ultra- and microfiltration membranes. Environ Sci Technol 38(18):4878-4883

Kang YW, Hwang KY (2000) Effects of reaction conditions on the oxidation efficiency in the Fenton process. Water Res 34(10):2786-2790

Karakulski K, Kozlowski A, Morawski AW (1995) Purification of oily wastewater by ultrafiltration. Sep Technol 5(4):197-205

Kitis M, Adams CD, Daigger GT (1999) The effects of Fenton's reagent pretreatment on the biodegradability of nonionic surfactants. Water Res 33(11):2561-2568

Lin SH, Lan WJ (1998) Waste oil/water emulsion treatment by membrane processes. J Hazard Mater 59(2-3):189-199

Lin SH, Lin CM, Leu HC (1999) Operating characteristics and kinetic studies of surfactant wastewater treatment by fenton oxidation. Water Res 33(7):1735-1741

Marchese J, Ochoa NA, Pagliero C, Almandoz C (2000) Pilot-scale ultrafiltration of an emulsified oil wastewater. Environ Sci Technol 34(14):2990-2996

Moulai-Mostefa N, Akoum O, Nedjihoui M, Ding L, Jaffrin MY (2007) Comparison between rotating disk and vibratory membranes in the ultrafiltration of oil-in-water emulsions. Desalination 206(1-3):494-498

Moulai-Mostefa N, Frappart M, Akoum O, Ding LH, Jaffrin MY (2010) Separation of water from metal working emulsions by ultrafiltration using vibratory membranes. J Hazard Mater 177(1-3):978-982

Neyens E, Baeyens J (2003) A review of classic Fenton's peroxidation as an advanced oxidation technique. J Hazard Mater 98(1-3):33-50

Pignatello JJ, Oliveros E, MacKay A (2006) Advanced oxidation processes for organic contaminant destruction based on the Fenton reaction and related chemistry. Crit Rev Environ Sci Technol 36(1):1-84

Shon HK, Vigneswaran S, Snyder SA (2006) Effluent organic matter (EfOM) in wastewater: constituents, effects, and treatment. Crit Rev Environ Sci Technol 36(4):327-374

Siedlecka EM, Stepnowski P (2007) Effect of chlorides and sulfates on the performance of a Fe ${ }^{3+} / \mathrm{H}_{2} \mathrm{O}_{2}$ Fenton-like system in the degradation of methyl tert-butyl ether and its byproducts. Water Environ Res 79(11):2318-2324

Zhong J, Sun XJ, Wang CL (2003) Treatment of oily wastewater produced from refinery processes using flocculation and ceramic membrane filtration. Sep Purif Technol 32(1-3):93-98 